\title{
State of the Art Radiation Therapy for Lung Cancer 2012: A Glimpse of the Future
}

Citation for published version (APA):

De Ruysscher, D., Belderbos, J., Reymen, B., van Elmpt, W., van Baardwijk, A., Wanders, R., Hoebers, F., Vooijs, M., Oellers, M., \& Lambin, P. (2013). State of the Art Radiation Therapy for Lung Cancer 2012: A Glimpse of the Future. Clinical Lung Cancer, 14(2), 89-95. https://doi.org/10.1016/j.cllc.2012.06.006

Document status and date:

Published: 01/03/2013

DOI:

10.1016/j.cllc.2012.06.006

Document Version:

Publisher's PDF, also known as Version of record

Document license:

Taverne

\section{Please check the document version of this publication:}

- A submitted manuscript is the version of the article upon submission and before peer-review. There can be important differences between the submitted version and the official published version of record.

People interested in the research are advised to contact the author for the final version of the publication, or visit the DOI to the publisher's website.

- The final author version and the galley proof are versions of the publication after peer review.

- The final published version features the final layout of the paper including the volume, issue and page numbers.

Link to publication

\footnotetext{
General rights rights.

- You may freely distribute the URL identifying the publication in the public portal. please follow below link for the End User Agreement:

www.umlib.nl/taverne-license

Take down policy

If you believe that this document breaches copyright please contact us at:

repository@maastrichtuniversity.nl

providing details and we will investigate your claim.
}

Copyright and moral rights for the publications made accessible in the public portal are retained by the authors and/or other copyright owners and it is a condition of accessing publications that users recognise and abide by the legal requirements associated with these

- Users may download and print one copy of any publication from the public portal for the purpose of private study or research.

- You may not further distribute the material or use it for any profit-making activity or commercial gain

If the publication is distributed under the terms of Article $25 \mathrm{fa}$ of the Dutch Copyright Act, indicated by the "Taverne" license above, 


\title{
State of the Art Radiation Therapy for Lung Cancer 2012: A Glimpse of the Future
}

\author{
Dirk De Ruysscher, ${ }^{1}$ José Belderbos, ${ }^{2}$ Bart Reymen, ${ }^{1}$ Wouter van Elmpt,${ }^{1}$ \\ Angela van Baardwijk, ${ }^{1}$ Rinus Wanders, ${ }^{1}$ Frank Hoebers, ${ }^{1}$ Marc Vooijs,${ }^{1}$ \\ Michel Öllers, ${ }^{1}$ Philippe Lambin ${ }^{1}$
}

\begin{abstract}
The prognosis of patients with lung cancer has improved over the past years. Patient selection, optimal sequencing of systemic and local treatments, and better surgical techniques, together with unprecedented improvements in imaging and computer technology and technical advances in radiation therapy planning and delivery has revolutionized radiation therapy in a short period of time. Among the most significant evolutions that have direct implications for daily practice are the more widespread use of stereotactic body radiation for stage I non-small-cell lung cancer (NSCLC), concurrent chemoradiation for stage III NSCLC, the implementation of 4-dimensional computed tomography and positron emission tomography, adaptive radiation therapy strategies, optimizing the timing of chest radiation therapy for limited disease small-cell lung cancer (SCLC) and prophylactic cranial irradiation for extensive disease SCLC. Molecular-based individualized radiation therapy dose prescription, which goes hand in hand with the realization of decision-support systems and the introduction of proton therapy centers give only a glimpse of what the future will bring.
\end{abstract}

\section{Clinical Lung Cancer, Vol. 14, No. 2, 89-95 @ 2013 Elsevier Inc. All rights reserved. \\ Keywords: Decision support, Individualized, Non-small-cell lung cancer, Radiation therapy, Small-cell lung cancer, Tumor heterogeneity}

\section{Introduction}

Lung cancer remains 1 of the most lethal and frequent malignancies in the world. ${ }^{1}$ After diagnosis, most patients with non-small-cell lung cancer (NSCLC) or small-cell lung cancer (SCLC) still die of their disease. Nevertheless, survival has slowly been increased, it has been realized that even in the metastatic setting, long-term survivors in selected patients with a few brain or adrenal metastases may be achieved with radical systemic and local treatment. ${ }^{2}$ In SCLC, the integration of chemotherapy and thoracic radiation therapy (RT) has

${ }^{1}$ Department of Radiation Oncology (MAASTRO clinic), GROW - School for Oncology and Developmental Biology, Maastricht University Medical Centre, Maastricht, The Netherlands

${ }^{2}$ Department of Radiation Oncology, The Netherlands Cancer Institute/Antoni van Leeuwenhoek Hospital, Amsterdam, The Netherlands

Submitted: Apr 24, 2012; Revised: Jun 15, 2012; Accepted: Jun 18, 2012; Epub: Jul 31,2012

Address for correspondence: Dirk De Ruysscher, MD, PhD, Department of Radiation Oncology (MAASTRO), GROW School for Oncology and Developmental Biology, Maastricht University Medical Center Maastricht (MUCM+), Maastricht, The Netherlands

Fax: +31-(0)88-44-55-667; e-mail contact: dirk.deruysscher@maastro.nl been elucidated and prophylactic cranial irradiation (PCI) has shown to prolong survival in patients with extensive disease (ED) SCLC.

In this review, we will focus on recent advances made in RT. In our view, most significant already for daily practice are the use of stereotactic body radiation (SBRT) also known as stereotactic ablative RT (SABR) for stage I NSCLC, ${ }^{3}$ concurrent chemoradiation for stage III NSCLC, the implementation of 4-dimensional (4D) computed tomography (CT) and positron emission tomography (PET), and adaptive RT strategies, the better integration of chest RT and chemotherapy for limited disease (LD) SCLC and PCI for ED SCLC.

\section{Stereotactic Ablative RT for Stage I NSCLC}

In SABR, a few fractions of very high doses of radiation are delivered to small tumors that are located in selected lung regions (eg, those remote from the more susceptible central mediastinal structures such as the main bronchi, large vessels, and the esophagus). It is a new treatment option for early stage NSCLC in inoperable patients. The advantages of SABR compared with conventional irradiation are a short overall treatment time (1-2 weeks) and a high biological effective dose. The possibility to minimize the number of 


\section{Radiation Therapy in 2012 and a Glimpse of the Future}

treatment sessions is an obvious benefit for medical inoperable patients suffering from cardiopulmonary disease and/or other comorbidities or simply because of their old age. SABR requires highly specialized RT treatment preparation and execution techniques including 4D respiration correlated CT scans and image-guided RT allowing precise patient positioning.

When 54-60 Gy in 3 fractions is delivered to patients with medically inoperable and peripheral located stage I NSCLC, local tumor control rates exceed $85 \%$ at 2 years, with approximately $5 \%$ subsequent estimated risk of pulmonary complications. For lesions with attachment to or close to the chest wall, the fractionation schedule of SBRT is adapted by delivering 8 fractions (7.5 Gy each), and analogous outcomes as with the 3 -fraction regimen have been described. ${ }^{4}$ It was demonstrated that a low pretreatment forces expiratory volume1 and/or diffusion capacity of the lungs for carbon monoxide alone should not be used to exclude patients with NSCLC from treatment with SBRT. ${ }^{5}$ Although no phase III trials have been published comparing surgery with SBRT, the introduction of SBRT improved the survival of medically inoperable stage I NSCLC patients in a population-based analysis in The Netherlands. ${ }^{6}$

In the follow-up after treatment of these patients, CT and ${ }^{18} \mathrm{~F}$ deoxyglucose (FDG)-PET scans appear different after conventional RT, with the development of a mass-like consolidation on CT or persistent FDG uptake being described as long as 3 years and more posttherapy. $^{7,8}$

\section{Concurrent Chemoradiation for Stage III NSCLC}

After the superiority of induction chemotherapy followed by RT over RT alone was shown, ${ }^{9}$ several randomized studies and 1 metaanalysis based on updated individual patient data have demonstrated a significant survival gain with concurrent chemoradiation compared with the sequential Schedule 10. The survival at 5 years increased from approximately $10 \%$ with sequential chemoradiation to approximately $15 \%$ with the concurrent approach. This improved survival has been attributed to improved local tumor control without affecting the incidence of distant metastases. ${ }^{10}$ This improved survival is at the expense of a higher incidence of severe (though reversible) esophagitis, occurring in 20\%-30\% of patients. No increased lung toxicity was observed in the concurrent regimens. The trials all have been performed in the pre-PET era, however, current state of the art staging examinations (brain imaging and FDG-PET scanning) were not performed. For the suboptimal staged patients in these trials, according to current standards, the influence of improved local control positively affected the overall survival. The RT techniques used in the reported trials were essentially 2-dimensional- and sometimes 3-Dbased without advanced dose calculation algorithms such as anisotropic analytical algorithm or superposition-convolution that take into account the dose of secondary photons and electrons and adaptive protocols, all of which were not available at the time when these studies were performed. The absolute long-term survival rates are thus likely to be higher in more recent series using modern delivery and verification techniques.

Because of the still high local tumor recurrence rates in nonsurgical series, 2 large phase III studies have addressed the role of surgical resection after induction treatment. ${ }^{11,12}$ In the Lung Intergroup
Trial 0139, patients with resectable N2 disease were randomized between surgery and definitive chemoradiation after induction concurrent chemoradiation. ${ }^{11}$ In the EORTC (European Organization for Research and Treatment of Cancer) trial, patients with unresectable $\mathrm{N} 2$ disease who showed at least a minimal tumor response after 3 cycles of induction chemotherapy were randomized between RT and surgery. ${ }^{12}$ Both trials found identical 5-year survival rates in the surgical and the nonsurgical arms: approximately $25 \%$ in the Intergroup study (resectable tumors) and 15\% in the EORTC trial (unresectable cancers). Although vigorously debated, ${ }^{13}$ the results of these 2 randomized trials are in line with previous phase II studies. ${ }^{14,15}$ In comparison, patients with resectable N2 disease receiving only chemotherapy followed by surgical resection, several single-institution phase II studies showed 5-year survival rates of approximately $20 \%$, although subgroups may have a better outcome. ${ }^{16-18}$

Also in concurrent chemoradiation it is of utmost importance to avoid treatment delays. In a large series of the Radiation Therapy Oncology Group (RTOG), it was demonstrated that each day of treatment prolongation beyond approximately 6.5 weeks resulted in a $2 \%$ decrease of survival. ${ }^{19}$ It is therefore logical that the RTOG found a positive association between higher biological RT doses and improved long-term survival rates. ${ }^{20}$

It should also be stressed that concurrent chemotherapy and RT is only safe in patients with no or limited comorbidities, who are relatively young, and have adequate organ functions. In a prospective, population-based study, we estimated that only about $40 \%$ of the patients with stage III lung cancer are suitable for the concurrent approach. ${ }^{21}$ For the others, sequential chemotherapy and RT remains a reasonable alternative. Moreover, the search for improvements in the RT component of both sequential and concurrent chemo-RT continues. Apart from the combination of targeted drugs and RT and technical advances, altered fractionation schedules that move away from the classic 2 Gy per day, 5 days per week regimen, have been tested.

\section{Hyperfractionation}

The basis of hyperfractionation (HFX) is to exploit the different capacity of cancer cells and late responding normal tissues to recover from sublethal radiation damage, given that the time interval between the 2 fractions is sufficiently long. An adequate interfraction interval is not trivial as the estimated recovery half-time in human tissues is in the order of 4 to 8 hours. ${ }^{22}$ That HFX might be useful to improve the therapeutic ratio of RT is based on the difference in fractionation sensitivity between tumors and late-responding tissues. HFX with increased total dose compared with conventional fractionation may thus be an option to improve local control and survival in NSCLC, without increasing the risk of late normal tissue damage.

The combination of HFX with accelerated fractionation, leading to a short overall treatment time, was tested in the CHART (Continuous Hyperfractionated Accelerated Radiotherapy) trial. ${ }^{23}$ In this schedule, 54 Gy is delivered in 12 days (3 times 1.5 Gy per day). In a large phase III trial, CHART was compared with the conventional schedule of $60 \mathrm{~Gy}$ in 30 fractions. $^{7}$ In the CHART arm, the 3-year local tumor control was $17 \%$ versus $13 \%$ in the conventional arm, with corresponding 3-year survival rates of $20 \%$ versus $13 \%(P=$ .008). The CHART trial supported the hypothesis that accelerated 


\section{Dirk De Ruysscher et al}

proliferation of cancer cells is an important reason for treatment failure.

In the Eastern Cooperative Oncology Group trial 2597, patients were randomized after induction chemotherapy to conventional fractionation (64 Gy in 6.5 weeks) or hyperfractionated accelerated radiotherapy (HART) (57.5 Gy in 2.5 weeks). ${ }^{24}$ In the experimental arm, patients received 3 fractions of 1.5 Gy per day, 5 days a week. The HART trial closed prematurely after recruiting 144 of the planned 388 patients, because of low patient accrual and logistical issues. The study was therefore underpowered to detect the hypothesized improvement in median survival from 14 to 21 months. The actual observed median survival was 14.9 months after conventional fractionation and 20.3 months after HART $(P=.28)$, which is close to the a priori study hypothesis.

A phase II trial investigated induction chemotherapy combined with CHART in locally advanced NSCLC, in which 56 Gy was delivered in 36 fractions in 12 days. Toxicity observed was mild and the median overall survival was 15.7 months. ${ }^{25}$

The CHART regimen, but without irradiation during weekends, is "CHART Weekends Less" or CHARTWEL. ${ }^{26}$ In a phase III trial, 406 patients with NSCLC were randomized between RT to $60 \mathrm{~Gy} / 40$ fractions in 2.5 weeks (CHARTWEL) or $66 \mathrm{~Gy} / 33$ fractions in 6.5 weeks (conventional fractionation; CF). Overall, the outcome after CHARTWEL or CF was not different. The lower total dose in the CHARTWEL arm was compensated by the shorter overall treatment time, confirming a time factor for NSCLC. However, an exploratory analysis showed a significant trend for improved local tumor control after CHARTWEL versus CF with increasing Union Internationale Contre le Cancer (UICC), $\mathrm{T}$ or $\mathrm{N}$ stage $(P=.006-.025)$ and after neoadjuvant chemotherapy (hazard ratio, 0.48; range, 0.26-0.89; $P=.019$ ). The higher efficacy of CHARTWEL versus CF in advanced stages and after chemotherapy thus provides a basis for further trials on treatment intensification for locally advanced NSCLC. These studies are currently accruing in the United Kingdom.

\section{Trials of Altered RT Schedules in Lung Cancer}

Many randomized phase III trials have been performed in which in 1 arm the RT schedule was different from the standard 2 Gy per day, 5 days per week. ${ }^{27}$ When considering all studies, patients being treated with high-dose RT delivered in short treatment times, seem to have the best long-term survival. The results of a meta-analysis based on updated individual patient data are to be awaited.

\section{Individualized Accelerated RT}

The overwhelming majority of trials stratify patients according to the assigned specific radiation doses to different risk groups. As a consequence, an important proportion of patients (eg, those with large tumors or with cancers in the proximity of critical structures such as the spinal cord) will not be able to receive the prescribed dose and be excluded from the study because of normal tissue constraints. Patients with smaller, more conveniently situated cancers will easily attain the prescribed dose without increased risk of toxicity, thus theoretically being undertreated because higher radiation doses could have been but were not given. Ideally one would like to individualize $\mathrm{RT}$ doses and deliver the highest possible radiation dose according to the highest individual achievable radiation dose taking into account the wide diversity in patients with regard to localization, tumor size, and dose-limiting organs at risk. As stated earlier, to overcome repopulation the dose should be delivered in a short overall treatment time. It was estimated that applying such an individualized scheme a gain in tumor control probability of about $25 \%$ could be reached compared with a classical scheme of 60 Gy in 2-Gy fractions in 6 weeks. ${ }^{28}$ In a phase II trial van Baardwijk et al investigated such an individualized iso-toxic accelerated RT (INDAR) scheme in 166 patients treated with sequential chemoradiation or RT alone. ${ }^{29}$ Most patients had bulky, multiple nodal stage N2 or N3 disease. The target volume was defined as the primary tumor and the pretreatment involved lymph nodes on FDG-PET-CT scan. The radiation dose was individually escalated until a dose-limiting normal tissue constraint was reached: a maximal mean lung dose of $19 \mathrm{~Gy}$, a maximal dose of 54 Gy for the spinal cord, and a maximum of 70.2 Gy for centrally located structures, like the main bronchi. The INDAR scheme showed promising results with acceptable toxicity: approximately $20 \%$ of acute grade 3 and $2.4 \%$ of acute grade 4 toxicity and $<5 \%$ of grade 3 late toxicity. With a median follow up of 32 months, the median overall survival was 21 months with a 2 -year overall survival of $45 \%$. INDAR was subsequently tested in concurrent chemo-RT in a group of 137 patients with stage III NSCLC. ${ }^{30}$ A median dose of 65 Gy was given in $<5$ weeks. Although this scheme showed more acute grade 3 toxicity, this consisted of mainly transient esophagitis. With a median follow-up of 21 months, the estimated median overall survival was 22.3 months. However, more mature results need to be awaited.

Another strategy to further individualize radiation treatment is to develop an assay to predict toxicity of organs at risk. This might be based on biomarkers like cytokines interleukin- 6 or transforming growth factor- $\beta 1$, or image-based. However data are still limited, ${ }^{31,32}$ and cannot be implemented in daily practice yet. Nomograms based on clinical and other parameters offer already now a practical way to define risk groups with reasonable accuracy. ${ }^{33,34}$

\section{Radiation Therapy Target Determination}

As the accuracy of FDG-PET is higher than CT for the staging of mediastinal lymph nodes, the incorporation of PET in the treatment planning process of RT has received a lot of attention. In many theoretic studies in NSCLC, the use of PET has resulted in smaller radiation fields which may lead to fewer side effects or to the possibility of radiation dose-escalation with the aim to improve local tumor control. ${ }^{35,36}$ Prospective studies indeed showed that selective mediastinal node irradiation based on FDG-PET scans did not lead to higher isolated nodal recurrences. ${ }^{37,38}$

Another important feature to support FDG-PET integration in RT planning, is that it reduces the variability of tumor delineation among radiation oncologists ${ }^{39-41}$ and even allows for automatic tumor delineation where the computer provides radiation oncologists with delineations that can be edited. ${ }^{42}$ The latter is very important, for the resolution of clinical PET scanners is approximately 5-7 mm, edges are blurred, and movements interfere significantly with PET signals. 4D-PET-CT scans may therefore become another step forward in tumor target delineation. 


\section{Radiation Therapy in 2012 and a Glimpse of the Future}

It is highly likely that FDG-PET could help identify therapyresistant areas within the tumor that could be eradicated if a higher radiation dose was given and hence lead to a better local control and survival. ${ }^{43,44}$ Dose escalation on the high FDG-PET area within the tumor is currently pursued in ongoing trials.

\section{Strategies to Deal With a Moving Lung Tumor}

A conventional planning CT scan consists of images without time information from the moving lung tumor and anatomy of the patient pretreatment. This 3-D planning CT scan is an arbitrary snapshot of the anatomy at a random moment of the breathing phase. During treatment, the patient is breathing freely, which results in a tumor position uncertainty. To overcome this tumor position uncertainty several strategies are currently introduced:

(1) Gated RT; the tumor is irradiated only during a part of the breathing cycle (gating window). During gated RT, the respiration is measured externally by respiration sensors (eg, skin markers or belt) and/or internally using fluoroscopy ${ }^{45,46}$ to determine when the beam should be on and off. Gated treatment is mostly performed with patients free-breathing, ${ }^{46}$ however, breath-hold irradiation ${ }^{47}$ is also possible. Gating is generally performed in exhalation, because the exhale respiration phase is more reproducible and takes longer than inspiration.

(2) Tumor tracking (irradiating the tumor dynamically with a moving beam $)^{48}$ results in similar target volumes as gating. This technique is still under development at various centers and not applied in a routine setting.

(3) The use of a midventilation (MidV) planning CT scan for treatment planning increases geometrical accuracy. The MidV CT scan represents the tumor in its time-averaged position over the respiratory cycle. ${ }^{49}$ Using this MidV planning CT scan, the systematic deviation from its average position due to breathing motion can be reduced to nearly 0 , permitting a significant reduction of the treatment margin needed to correct for tumor motion.

However, with all scenarios described above, one has to be careful with baseline differences of the tumor position during the course of treatment. Such a difference might be tackled using image-guided or adaptive RT (see further).

\section{Intensity Modulated RT}

Intensity modulated RT (IMRT) requires a treatment planning that is almost entirely computerized, and represents a major change in the way RT treatments are planned. ${ }^{50}$ IMRT is a technical improvement of 3-D conformal RT by applying nonuniform (modulated) radiation intensity over the treatment fields. IMRT has enabled larger tumor volumes to be irradiated to a radical dose (because of a steeper dose fall-off). Schwarz et $\mathrm{al}^{51}$ analyzed IMRT dose distributions in the organs at risk and compared the results with conventional conformal RT techniques in 10 lung cancer patients participating in a dose escalation trial. The constraints used for the organs at risk were the same as the constraints used in a dose escalation trial using 3-D conformal RT. Schwarz concluded that the IMRT technique together with the acceptance of dose heterogeneity within the target volume allowed further increase of radiation dose, especially in patients with mediastinal involve- ment of their lung cancer (patients with large and concave tumors). Using IMRT a dose escalation of 20\%-35\% compared with 3-D conformal RT was achieved. ${ }^{51}$

\section{Image-Guided RT}

For the irradiation of lung cancer geometrical uncertainties like patient setup variation, organ motion, and delineation variation must be kept as low as possible.

Modern linear accelerators equipped with multileaf collimators and in-room imaging options have enabled the delivery of more accurate irradiation. The multileaf collimators are used to automatically create individualized treatment fields and the in-room imaging options facilitate image-guided RT (IGRT): in IGRT images of the patient acquired just before a treatment fraction are used to measure or estimate the position of the patient's anatomy at a given time to ensure correct placement of the radiation treatment beams. IGRT considerably increases the precision of RT as lung tumors move during treatment and change between treatment fractions because of tumor shrinkage and radiation-induced pulmonary changes.

Because of the high level of accuracy reached using IGRT delivery the margins around the tumor can be reduced and we can safely irradiate to higher doses the lung tumor and pathologic lymph nodes. IGRT can be performed using:

(1) Electronic portal imaging devices (EPIDs) that image the radiation that has passed through the patient (megavolt imaging). The EPID can be used to reduce setup errors to monitor target position during radiation delivery by acquiring megavoltage CT scans. ${ }^{52,53}$

(2) Kilovoltage or MV x-ray tubes and detectors that image the patient can be used for pre- or posttreatment cone beam CT acquisition, provide superior tumor visualization compared with MV imaging. For real time tumor tracking images radio-opaque markers are particularly useful. These radio-opaque markers should be implanted into or near the tumor. Verification of tumor motion at the time of treatment may be performed using $4 \mathrm{D}$ cone beam CT scanning. ${ }^{53}$

(3) Optical monitoring of a point (or points) on the patient surface gives real-time information. The optical signals can be used to monitor respiration and patient motion for respiratory gated RT, and also be combined with $\mathrm{kV}$ or MV imaging data to estimate internal target positions. ${ }^{54}$

(4) Magnetic resonance imaging is a newer modality for inroom imaging for lung tumors under development by several groups.

Several authors have studied interfraction patient setup errors and reported 4-mm systematic and 3-mm random errors (1 SD). Setup correction protocols have been developed to reduce these patient setup errors. Using simple off-line correction protocols (imaging approximately one-third of the fractions), the systematic error can be reduced by a factor 2 to 3 .

More recently, considerable day-to-day variation of the tumor relative to the bony anatomy (baseline shifts) were observed. ${ }^{55,56}$ Tumor visualization or accurate surrogates are required to correct for these baseline shifts. In the absence of such corrections, the application of gated treatment delivery is not recommended.

The type of correction strategy applied to reduce geometrical uncertainties needs to be in balance between workload and precision 


\section{Dirk De Ruysscher et al}

and depend on the fractionation scheme prescribed. For conventional fractionation using a large number of fractions, a less precise correction strategy is generally considered adequate.

\section{Adaptive RT}

Computed tomography image-guided (either cone-beam or conventional CT) RT, allows repetitive imaging of the anatomy in 3-D during the 5 to 6 weeks of a radiation course. During the course of treatment, tumor progression or regression may be seen as well as other anatomical changes within the thorax requiring replanning and/or treatment adaptation. In a study by Schaake et $\mathrm{al}^{57}$ anatomic changes during conventional RT with curative intent was quantified. In this study, 114 consecutive lung cancer patients were included, treated with conventional RT with a dose of 45-88 Gy over 5-6 weeks for cT1N0 to cT4N3 NSCLC. Patients received repetitive cone-beam CT scans for an off-line setup correction protocol. The tumor volume was delineated on the planning CT and the conebeam CT each treatment week. The occurrence or resolution of atelectasis, and pleural effusion were scored qualitatively. In onethird of the lung cancer patients, tumor regression was seen over the 5-6 week course of conventional treatment. Forty-seven patients (41\%) manifested considerable anatomical changes in at least 1 of the categories. Further research is needed to monitor anatomical changes during treatment and quantify whether the delivered dose meets the treatment intent.

\section{Timing of Chest RT for LD-SCLC}

Many phase III studies have investigated the timing of chest radiation in LD-SCLC (reviewed in Fried et al, ${ }^{58}$ and Pijls-Johannesma et $\mathrm{al}^{59}$ ). When all studies were considered, the delivery of early versus late thoracic irradiation did not influence the survival. However, when the most active chemotherapy regimen (platinum-based) was administered concomitantly with chest RT, long-term survival was increased at the expense of a higher incidence of severe, though transient esophagitis. At 5 years, the survival was significantly higher when chest RT was given early (ie, within 30 days after the initiation of chemotherapy), representing a 5-year survival rate of $20.2 \%$ for early versus $13.8 \%$ for late thoracic RT. In a pivotal phase III study, ${ }^{60}$ decreasing the overall treatment time of chest RT from 5 weeks (2 Gy once per day) to 3 weeks (1.5 Gy twice per day), while keeping the total radiation dose to $45 \mathrm{~Gy}$, increased the 5-year survival from $16 \%$ to $26 \%$.

Early, concurrent chemotherapy with accelerated radiation may result in approximately $20 \%-30 \%$ grade 3 acute esophagitis, which contrasts with approximately $15 \%$ in early, concurrent, nonaccelerated RT and approximately $5 \%$ in sequential schedules. Interestingly, lung toxicity appeared not to be influenced by the timing of RT.

It has been hypothesized ${ }^{61}$ that accelerated repopulation is triggered by the first dose of any effective cytotoxic agent and that in order to obtain local tumor control, the last tumor clonogen should be killed by the last irradiation. It follows from these 2 assumptions that the long-term tumor cell survival should decrease with increasing time between the start of any treatment to the end of RT (SER). A meta-analysis of published data showed superior long-term survival if the SER was kept to less than 30 days in LD-SCLC. ${ }^{61}$
These results are consistent with accelerated proliferation of tumor clonogens triggered by RT and or chemotherapy. As expected, accelerated treatments also cause more toxicity in rapidly proliferating tissues such as the esophageal mucosa.

In conclusion, for limited-stage small cell lung cancer, current evidence supports the early administration of thoracic RT with concurrent cisplatin and etoposide chemotherapy.

In the only prospective study that was specifically designed to selectively irradiate CT enlarged nodal areas in limited disease SCLC, in $11 \%$ of the patients, isolated nodal failures were observed. ${ }^{62} \mathrm{Be}-$ cause of the higher staging accuracy of FDG-PET also in SCLC, a prospective study in which the nodal target volume was defined on the basis of FDG-PET was performed. ${ }^{63}$ Only 2 patients out of 60 patients included (3\%) developed isolated nodal failures. Because of the reduced target volume irradiated after FDG-PET treatment preparation compared with elective nodal irradiation the incidence of severe esophagitis can be reduced, even in these often high-volume tumors. ${ }^{63}$ These findings were subsequently confirmed in an American retrospective study. ${ }^{64}$

\section{Prophylactic Cranial Irradiation for ED-SCLC}

Prophylactic cranial irradiation is standard treatment in stage I-III SCLC, but its role in stage IV has only recently been studied in randomized studies.

In patients with ED-SCLC who had any response to chemotherapy, PCI was compared with no PCI in a prospective, randomized study. ${ }^{65}$ Patients in the PCI group had a lower risk of symptomatic brain metastases. The cumulative risk of symptomatic brain metastases within 1 year was $14.6 \%$ in the irradiation group (95\% confidence interval [CI], 8.3-20.9) and 40.4\% in the control group (95\% CI, 32.1-48.6). Irradiation was associated with an increase in median disease-free survival from 12.0 to 14.7 weeks and in median overall survival from 5.4 to 6.7 months after randomization. The 1-year survival rate was $27.1 \%(95 \% \mathrm{CI}, 19.4-35.5)$ in the PCI group and $13.3 \%$ (95\% CI, 8.1-19.9) in the control group. Irradiation had side effects, especially fatigue but did not seem to have a clinically significant effect on global health status, although the long-term toxicity was not examined.

\section{Conclusions}

Beside undisputable advances in systemic treatment and improved surgical techniques, RT has further improved. Among the most significant evolution that have direct influence in standard practice are the more wide-spread use of SABR for stage I NSCLC, concurrent chemoradiation for stage III NSCLC, the timing of chest RT for LD SCLC and PCI for ED-SCLC, which all contributed to the better survival of patients with lung cancer. The respiration correlated $4 \mathrm{D}$ CT treatment planning, IMRT and image-guided techniques like cone beam CT scanning open a completely new episode of high geometrical precision RT, which may be further improved with new beam qualities such as proton therapy. ${ }^{66}$

\section{Disclosure}

None declared. 


\section{Radiation Therapy in 2012 and a Glimpse of the Future}

\section{References}

1. Simard EP, Ward EM, Siegel R, et al. Cancers with increasing incidence trends in the United States: 1999 through 2008. CA Cancer J Clin, Published online January 4, 2012; doi: 10.3322/caac.20141

2. Rubin P, Brasacchio R, Katz A. Solitary metastases: illusion versus reality. Semin Radiat Oncol 2006; 16:120-30.

3. Timmerman R, Paulus R, Galvin J, et al. Stereotactic body radiation therapy for inoperable early stage lung cancer. JAMA 2010; 303:1070-6.

4. Bongers EM, Haasbeek CJ, Lagerwaard FJ, et al. Incidence and risk factors for chest wall toxicity after risk-adapted stereotactic radiotherapy for early-stage lung cancer. J Thorac Oncol 2011; 6:2052-7.

5. Guckenberger M, Kestin LL, Hope AJ, et al. Is there a lower limit of pretreatment pulmonary function for safe and effective stereotactic body radiotherapy for earlystage non-small cell lung cancer? J Thorac Oncol 2012; 7:542-51.

6. Palma D, Visser O, Lagerwaard FJ, et al. Impact of introducing stereotactic lung radiotherapy for elderly patients with stage I non-small-cell lung cancer: a population-based time-trend analysis. J Clin Oncol 2010; 28:5153-9.

7. Hoopes DJ, Tann M, Fletcher JW, et al. FDG-PET and stereotactic body radiotherapy (SBRT) for stage I non-small-cell lung cancer. Lung Cancer 2007 56:229-34.

8. Dahele M, Palma D, Lagerwaard F, et al. Radiological changes after stereotactic radiotherapy for stage I lung cancer. J Thorac Oncol 2011; 6:1221-8.

9. Chemotherapy in non-small cell lung cancer: a meta-analysis using updated data on individual patients from 52 randomised clinical trials. Non-small Cell Lung Cancer Collaborative Group. BMJ 1995; 311:899-909.

10. Aupérin A, Le Péchoux C, Rolland E, et al. Meta-analysis of concomitant versus sequential radiochemotherapy in locally advanced non-small-cell lung cancer. JClin Oncol 2010; 28:2181-90.

11. Albain KS, Swann RS, Rusch VW, et al. Radiotherapy plus chemotherapy with or without surgical resection for stage III non-small-cell lung cancer: a phase III randomised controlled trial. Lancet 2009; 374:379-86.

12. van Meerbeeck JP, Kramer GW, Van Schil PE, et al. Randomized controlled trial of resection versus radiotherapy after induction chemotherapy in stage IIIA-N2 nonsmall-cell lung cancer. J Natl Cancer Inst 2007; 99:442-50.

13. Vansteenkiste J, Betticher D, Eberhardt W, et al. Randomized controlled trial of resection versus radiotherapy after induction chemotherapy in stage IIIA-N2 nonsmall cell lung cancer. J Thorac Oncol 2007; 2:684-5.

14. Albain KS, Rusch VW, Crowley JJ, et al. Concurrent cisplatin/etoposide plus chest radiotherapy followed by surgery for stages IIIA (N2) and IIIB non-small-cell lung cancer: mature results of southwest Oncology Group phase II study 8805. J Clin Oncol 1995; 13:1880-92.

15. Pöttgen C, Eberhardt W, Bildat S, et al. Induction chemotherapy followed by concurrent chemotherapy and definitive high-dose radiotherapy for patients with locally advanced non-small-cell lung cancer (stages IIIa/IIIb): a pilot phase I/II trial. Ann Oncol 2002; 13:403-11.

16. Lorent N, De Leyn P, Lievens $Y$, et al. Long-term survival of surgically staged IIIA-N2 non-small-cell lung cancer treated with surgical combined modality approach: analysis of a 7-year prospective experience. Ann Oncol 2004; 15:1645-53.

17. Betticher DC, Hsu Schmitz SF, Tötsch M, et al. Prognostic factors affecting longterm outcomes in patients with resected stage IIIA pN2 non-small-cell lung cancer: 5-year follow-up of a phase II study. Br J Cancer 2006; 94:1099-106.

18. Garrido P, González-Larriba JL, Insa A, et al. Long-term survival associated with complete resection after induction chemotherapy in stage IIIA (N2) and IIIB (T4N0-1) non small-cell lung cancer patients: the Spanish Lung Cancer Group trial 9901. J Clin Oncol 2007; 25:4736-42.

19. Machtay M, Hsu C, Komaki R, et al. Effect of overall treatment time on outcomes after concurrent chemoradiation for locally advanced non-small-cell lung carcinoma: analysis of the radiation therapy Oncology Group (RTOG) experience. Int Radiat Oncol Biol Phys 2005; 63:667-71.

20. Machtay M, Bae K, Movsas B, et al. Higher biologically effective dose of radiotherapy is associated with improved outcomes for locally advanced non-small cell lung carcinoma treated with chemoradiation: an analysis of the radiation therapy Oncology Group. Int J Radiat Oncol Biol Phys 2012; 82:425-34

21. De Ruysscher D, Botterweck A, Dirx M, et al. Eligibility for concurrent chemotherapy and radiotherapy of locally advanced lung cancer patients: a prospective, population-based study. Ann Oncol 2009; 20:98-102

22. De Ruysscher D, Khoo V, Bentzen SM. Biological basis of fractionation and timing of radiotherapy. In: Pass HI, Carbone DP, Johnson DH, et al, eds. Lung Cancer: Principles and Practice, 4th ed. Philadelphia: Lippincott Williams \& Wilkins; 2009, pp. 569-588.

23. Saunders M, Dische S, Barrett A, et al. Continuous, hyperfractionated, accelerated radiotherapy (CHART) versus conventional radiotherapy in non-small cell lung cancer: mature data from the randomised multicentre trial. CHART Steering Committee. Radiother Oncol 1999; 52:137-48.

24. Belani CP, Wang W, Johnson DH, et al. Phase III study of the Eastern Cooperative Oncology Group (ECOG 2597): induction chemotherapy followed by either standard thoracic radiotherapy or hyperfractionated accelerated radiotherapy for patients with unresectable stage IIIA and B non-small-cell lung cancer. J Clin Oncol 2005; 23:3760-7.

25. Jenkins P, Anderson S, Wronski S, et al. A phase II trial of induction chemotherapy followed by continuous hyperfractionated accelerated radiotherapy in locally advanced non-small-cell lung cancer. Radiother Oncol 2009; 93:396-401.
26. Baumann M, Herrmann T, Koch R, et al. Final results of the randomized phase III CHARTWEL-trial (ARO 97-1) comparing hyperfractionated-accelerated versus conventionally fractionated radiotherapy in non-small cell lung cancer (NSCLC). Radiother Oncol 2011; 100:76-85.

27. Stuschke M, Pottgen C. Altered fractionation schemes in radiotherapy. Front Radiat Ther Oncol 2010; 42:150-6.

28. van Baardwijk A, Bosmans G, Bentzen SM, et al. Radiation dose prescription for non-small-cell lung cancer according to normal tissue dose constraints: an in silico clinical trial. Int J Radiat Oncol Biol Phys 2008; 71:1103-10.

29. van Baardwijk A, Wanders S, Boersma L, et al. Mature results of an individualized radiation dose prescription study based on normal tissue constraints in stages I to III non-small-cell lung cancer. J Clin Oncol 2010; 28:1380-6.

30. van Baardwijk A, Wanders R, Reymen B, et al. First results of a phase II tria investigating individualized dose-escalation based on normal tissue constraints in Concurrent chemo-radiation for locally advanced non-small cell lung cancer. Eur J Cancer, Published online May 17, 2012 [Epub ahead of print].

31. Kong FM, Ao X, Wang L, et al. The use of blood biomarkers to predict radiation lung toxicity: a potential strategy to individualize thoracic radiation therapy. Cancer Contr 2008; 15:140-50.

32. De Ruysscher D, Houben A, Aerts HJ, et al. Increased (18)F-deoxyglucose uptake in the lung during the first weeks of radiotherapy is correlated with subsequent Radiation-induced lung toxicity (RILT): a prospective pilot study. Radiother Oncol 2009; 91:415-20.

33. Dehing-Oberije C, Aerts H, Yu S, et al. Development and validation of a prognostic model using blood biomarker information for prediction of survival of non-smallcell lung cancer patients treated with combined chemotherapy and radiation or radiotherapy alone (NCT00181519, NCT00573040, and NCT00572325). Int J Radiat Oncol Biol Phys 2011; 81:360-8.

34. Dehing-Oberije C, De Ruysscher D, Petit S, et al. Development, external validation and clinical usefulness of a practical prediction model for radiation-induced dysphagia in lung cancer patients. Radiother Oncol 2010; 97:455-61.

35. Nestle U, Kremp S, Grosu AL. Practical integration of [18F]-FDG-PET and PET-CT in the planning of radiotherapy for non-small cell lung cancer (NSCLC) the technical basis, ICRU-target volumes, problems, perspectives. Radiother Onco 2006; 81:209-25.

36. van der Wel A, Nijsten S, Hochstenbag M, et al. Increased therapeutic ratio by 18FDG-PET CT planning in patients with clinical CT stage N2-N3M0 non-smallcell lung cancer: a modeling study. Int J Radiat Oncol Biol Phys 2005; 61:649-55.

37. De Ruysscher D, Wanders S, van Haren E, et al. Selective mediastinal node irradiation based on FDG-PET scan data in patients with non-small-cell lung cancer: a prospective clinical study. Int J Radiat Oncol Biol Phys 2005; 62:988-94.

38. Belderbos JS, Heemsbergen WD, De Jaeger K, et al. Final results of a phase I/II dose escalation trial in non-small-cell lung cancer using three-dimensional conforma radiotherapy. Int J Radiat Oncol Biol Phys 2006; 66:126-34

39. Steenbakkers RJ, Duppen JC, Fitton I, et al. Observer variation in target volume delineation of lung cancer related to radiation oncologist-computer interaction: 'Big Brother' evaluation. Radiother Oncol 2005; 77:182-90.

40. Caldwell CB, Mah K, Ung YC, et al. Observer variation in contouring gros tumor volume in patients with poorly defined non-small-cell lung tumors on CT: the impact of 18FDG-hybrid PET fusion. Int I Radiat Oncol Biol Phy 2001; 51:923-31.

41. Werner-Wasik M, Nelson AD, Choi W, et al. What is the best way to contour lung tumors on PET scans? Multiobserver validation of a gradient-based method using NSCLC digital PET phantom. Int I Radiat Oncol Biol Phys 2012; 82:1164-71.

42. van Baardwijk A, Bosmans G, Boersma L, et al. PET-CT-based auto-contouring in non-small-cell lung cancer correlates with pathology and reduces interobserver variability in the delineation of the primary tumor and involved nodal volumes. Int J Radiat Oncol Biol Phys 2007; 68:771-8.

43. Aerts HJ, Bosmans G, van Baardwijk AA, et al. Stability of $18 \mathrm{~F}$-deoxyglucose uptake locations within tumor during radiotherapy for NSCLC: a prospective study. Int J Radiat Oncol Biol Phys 2008; 71:1402-7.

44. Aerts HJ, van Baardwijk AA, Petit SF, et al. Identification of residual metabolicactive areas within individual NSCLC tumours using a pre-radiotherapy (18)fluorodeoxyglucose-PET-CT scan. Radiother Oncol 2009; 91:386-92.

45. Cui Y, Dy JG, Sharp GC, et al. Robust fluoroscopic respiratory gating for lung cancer radiotherapy without implanted fiducial markers. Phys Med Biol 2007; 52:741-55.

46. Keall PJ, Todor AD, Vedam SS, et al. On the use of EPID-based implanted marker tracking for 4D radiotherapy. Med Phys 2004; 31:3492-9.

47. Mageras GS, Yorke E. Deep inspiration breath hold and respiratory gating strategies for reducing organ motion in radiation treatment. Semin Radiat Oncol 2004; 14:65-75.

48. Keall PJ, Joshi S, Vedam SS, et al. Four-dimensional radiotherapy planning for DMLC-based respiratory motion tracking. Med Phys 2005; 32:942-51.

49. Wolthaus JW, Schneider C, Sonke JJ, et al. Mid-ventilation CT scan construction from four-dimensional respiration-correlated CT scans for radiotherapy planning of lung cancer patients. Int J Radiat Oncol Biol Phys 2006; 65:1560-71.

50. Grills IS, Yan D, Martinez AA, et al. Potential for reduced toxicity and dose escalation in the treatment of inoperable non-small-cell lung cancer: a comparison of intensity-modulated radiation therapy (IMRT), 3D conformal radiation, and elective nodal irradiation. Int J Radiat Oncol Biol Phys 2003; 57:875-90.

51. Schwarz M, Alber M, Lebesque JV, et al. Dose heterogeneity in the target volume and intensity-modulated radiotherapy to escalate the dose in the treatment of nonsmall-cell lung cancer. Int J Radiat Oncol Biol Phys 2005; 62:561-70. 


\section{Dirk De Ruysscher et al}

52. Berbeco RI, Hacker F, Ionascu D, et al. Clinical feasibility of using an EPID in CINE mode for image-guided verification of stereotactic body radiotherapy. Int $J$ Radiat Oncol Biol Phys 2007; 69:258-66.

53. Sonke JJ, Zijp L, Remeijer P, et al. Respiratory correlated cone beam CT. Med Phy 2005; 32:1176-86.

54. Cho B, Suh Y, Dieterich S, et al. A monoscopic method for real-time tumour tracking using combined occasional $\mathrm{x}$-ray imaging and continuous respiratory monitoring. Phys Med Biol 2008; 53:2837-55.

55. Purdie TG, Bissonnette JP, Franks K, et al. Cone-beam computed tomography for on-line image guidance of lung stereotactic radiotherapy: localization, verification, and intrafraction tumor position. Int J Radiat Oncol Biol Phys 2007; 68:243-52.

56. Sonke JJ, Lebesque J, van Herk M. Variability of four-dimensional computed tomography patient models. Int J Radiat Oncol Biol Phys 2008; 70:590-8.

57. Schaake E, Belderbos J, Rit $S$, et al. Detailed analysis of tumor regression during radical radiotherapy in lung cancer patients. I Thorac Oncol 2011; S6:S430-1.

58. Fried DB, Morris DE, Poole C, et al. Systematic review evaluating the timing of thoracic radiation therapy in combined modality therapy for limited-stage small-cell lung cancer. J Clin Oncol 2004; 22:4837-45.

59. Pijls-Johannesma M, De Ruysscher D, Vansteenkiste J, et al. Timing of chest radiotherapy in patients with limited stage small cell lung cancer: a systematic review and metaanalysis of randomised controlled trials. Cancer Treat Rev 2007; 33:461-73.
60. Turrisi AT 3rd, Kim K, Blum R, et al. Twice-daily compared with once-daily thoracic radiotherapy in limited small-cell lung cancer treated concurrently with cisplatin and etoposide. N Engl J Med 1999; 340:265-371.

61. De Ruysscher D, Pijls-Johannesma M, Bentzen SM, et al. Time between the first day of chemotherapy and the last day of chest radiation is the most important predictor of survival in limited-disease small-cell lung cancer. J Clin Oncol 2006 24:1057-63.

62. De Ruysscher D, Bremer RH, Koppe F, et al. Omission of elective node irradiation on basis of CT-scans in patients with limited disease small cell lung cancer: a phase II trial. Radiother Oncol 2006; 80:307-12.

63. van Loon J, De Ruysscher D, Wanders R, et al. Selective nodal irradiation on basis of (18)FDG-PET scans in limited-disease small-cell lung cancer: a prospective study. Int J Radiat Oncol Biol Phys 2010; 77:329-36.

64. Shirvani SM, Komaki R, Heymach JV, et al. Positron emission tomography/computed tomography-guided intensity-modulated radiotherapy for limited-stage small-cell lung cancer. Int J Radiat Oncol Biol Phys 2012; 82:e91-7.

65. Slotman B, Faivre-Finn C, Kramer G, et al. Prophylactic cranial irradiation in extensive small-cell lung cancer. $N$ Engl J Med 2007; 357:664-72.

66. De Ruysscher D, Mark Lodge M, Jones B, et al. Charged particles in radiotherapy: a 5-year update of a systematic review. Radiother Oncol 2012; 103:5-7. 